\title{
Progress in airline distribution systems: The threat of new entrants to incumbent players
}

\author{
Athina Sismanidou ${ }^{1}$, Miguel Palacios ${ }^{2}$, Javier Tafur $^{2}$ \\ ${ }^{1} \mathrm{E} A D$ A Business School (SP AIN); ${ }^{2}$ Universidad Politécnica de Madrid (SPAIN) \\ atids@yahoo.com; mipalacios@etsii.upm.es; javier.tafun@upm.es
}

Received October 2008

Accepted April 2009

\begin{abstract}
For decades, distribution has been a key ICT (Information and Communication Technology) area for airlines and this sector has been dominated by four (now three) Global Distribution Systems (GDSs) whose primacy has been threatened over the last four years by a set of new players, the so called GDS New Entrants (GNEs). GNEs emerged with the advent of the Internet and open source technology as 'disintermediation' facilitators and generated vast interest from airlines because they promised to reduce the cost of distribution.
\end{abstract}

This paper explores the impact of ICTs on airlines with a focus on GDSs. It provides an overview of the changing market dynamics, analyses the environment that led to the appearance of GNEs and pinpoints the issues behind their until now failure to provide a true alternative to the GDSs. This analysis complements existing academic research in that it clarifies critical issues in the air travel distribution field and provides an overview of current industry developments

Keywords: travel reservation systems; GDSs; airline industry; information and communication technologies 


\section{Introduction}

Internet technology and web based commerce have dramatically transformed the airline industry in the last ten years (Werthner and Klein, 2005). Information and Communication Technologies (ICTS) have always played a predominant role in the airline sector (Poon, 1993; Inkpen, 1994; O'Connor, 1999; Werthner and Klein, 1999) but with the advent of the Internet and open source technology their impact is becoming increasingly more crucial and evident (Buhalis, 2004; Jacobsen et al., 2008). As travellers embraced the Internet, this enabled airlines to bypass the traditional distribution pattern through travel agencies and sell direct to end consumers (European Commission, 2006). Web distribution combined with cheaper and more flexible technologies allowed new players on the market, low cost airlines (LCCS), to implement effective low-cost direct distribution strategies and intensify competition in the sector (Dennis 2007; Buhalis \& Law, 2008). Traditional airlines could not afford to rely on outdated distribution strategies and had to invest heavily in new technology to support their online Web sites, as post-September 11 harsh economic conditions and low-fare carriers transformed the marketplace and the needs and preferences of passengers changed (Franke, 2004; Binggeli \& Pompeo, 2005; Dobruszke, 2006)

Distribution has been a key ICT area for airlines for decades and this sector is now dominated by three Global Distribution Systems (GDSs) whose primacy has been threatened over the last three years by a set of new players, the so called GDS New Entrants (GNEs).

This paper explores the interaction between technology and airline dstribution with a focus on GDSs. It provides a comprehensive review of the changing market dynamics, analyses the environment that led to the appearance of the GNEs, and assesses the issues behind their until now failure to provide a true alternative to GDSs. Finally, the paper draws conclusions from extensive research in industry data sources as well as from academic literature and interviews with industry experts. The extraordinarily dynamic nature of airline distribution makes any conjectures about future developments in the sector sound like crystal-ball predictions but experts seem to agree on a number of trends that are here to stay. 


\section{The role of ICTs in the airline industry}

\subsection{ICTs as strategic tools}

Information technology is heavily embedded in all levels of airline operations. Recently, the term has been broadened to explicitly encompass the electronic communication field, and the abbreviation ICT (Information and Communication Technology) is now widely used (Buhalis 2004; Gholami, Emrouznejad \& Schmidt, 2008). Information and Communication technologies may be defined as "electronic means of capturing, processing, storing, and disseminating information" (Laudon \& Laudon, 2007) and provide new mechanisms for handling existing resources and information.

Information and Communication Technologies (ICTs) can provide powerful strategic and tactical tools for organizations, which, if properly applied and used, could bring great advantages in promoting and strengthening their competitiveness (Porter $2001,1985)$. Few other industries rely on so many partners to collaborate closely for delivering their products and few other value chains are as elaborate as the one for travel (Buhalis, 1998). All airlines rely heavily on ICTs for their operations and management and employ them for a wide range of business functions. As a result, ICTs can impact airline costs and operational efficiency and there is evidence that well managed ICTs can generate tremendous value for organisations (Lee, 2001).

\subsection{Areas of ICT usage in the airline industry}

The portfolio of solutions for airline planning and control ranges from network planning, code share handling and crew management, to pricing, price distribution and revenue management. Airline ICTs are further supplemented by business intelligence services, marketing and sales solutions. Figure 1 summarises the areas of ICT usage by airlines.

We can identify two main groups of airline business functions supported by ICTs. The first includes an airline's flight operational activities and the second its business management and control functions. As far as operations are concerned, ICTs contribute to the optimisation of flight related procedures and processes. Airline operations supported by ICTs include dispatch and coordination of flights and related resources namely crew, aircraft, passenger and freight processing, and airport facilities such as gates, ramps, baggage handling etc. From a business 
management and control point of view, airlines employ ICTs in most functions, from administrative tasks and accounting to financial management, human resources and procurement (Verville, 2003).

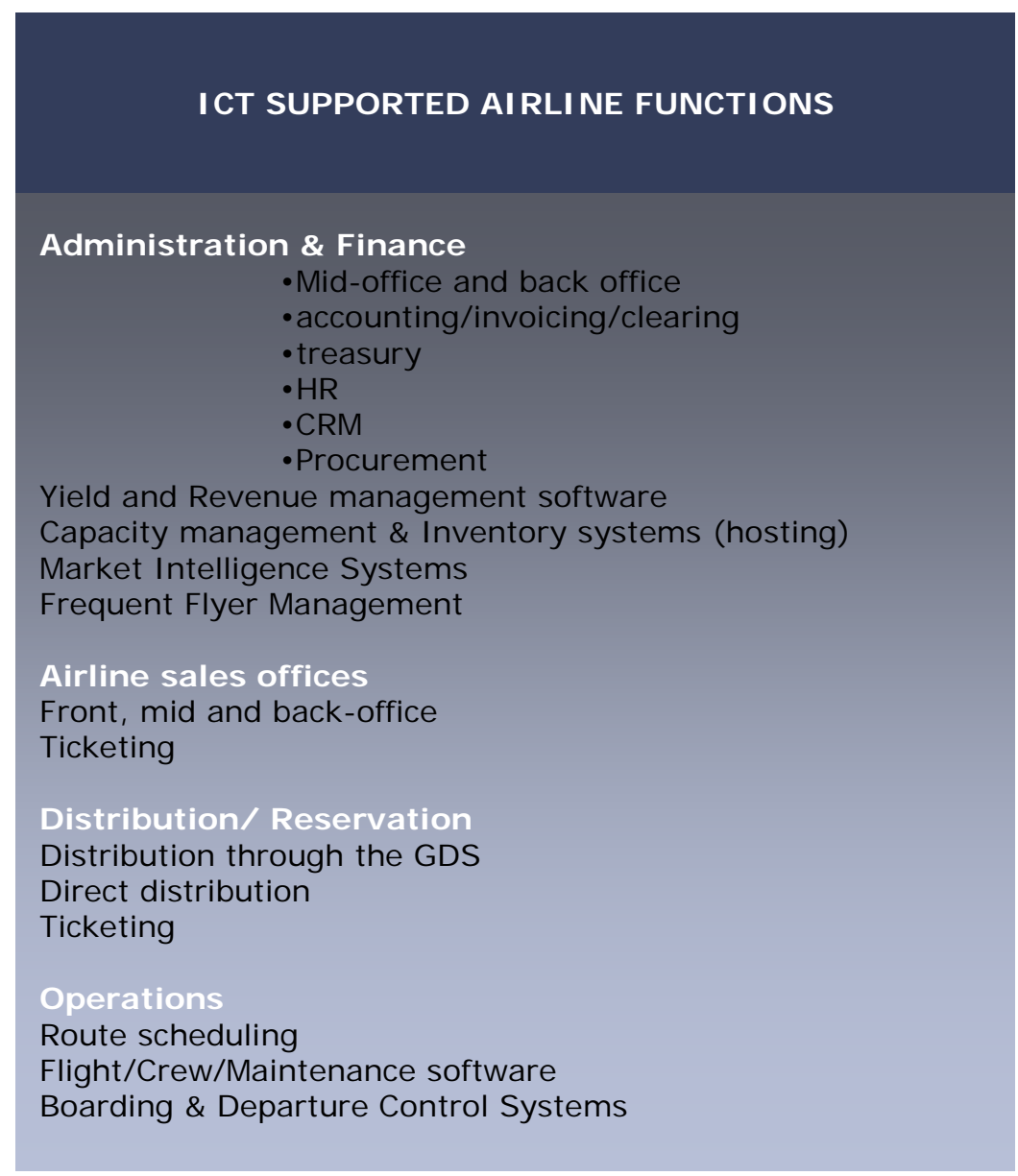

Figure 1. "Areas of ICT usage by airlines". Source: authors

Airlines use technology to develop and manage their business model as well as to monitor the external environment and competition, undertake revenue analysis, forecasting, maintain historical data, predict demand, and design desirable products. ICTs are critical for monitoring and forecasting the performance of Strategic Business Units (SBUs) and for deciding which markets airlines should penetrate and how. Routes and crew planning, frequency of service, choice of aircraft and developing relationships with strategic partners are key functions supported by ICTs (Buhalis, 1998). Strategic pricing and yield management are supported by running complex algorithms to establish best performance and profitability levels and optimisation and simulation tools are used heavily to 
maximise revenue in both network planning and revenue management processes (Mooney, 2003).

One of the most critical areas of ICTs' contribution in the airline industry has been distribution and collaboration with partners (Buhalis, 2004; Copeland, 1991; Copeland \& McKenney, 1988). Industry experts agree that the most significant recent technology factor affecting an airline's business has been the Internet which has shifted the playing field and undermined many of the schedule and pricing assumptions of the traditional airline industry as will be explained in section 4 of this paper.

\section{Airline distribution through GDSs}

Airline distribution has for many years been synonymous to Central Reservation Systems (CRSs), later termed Global Distribution Systems (GDSs). GDSs have served as the nexus of electronic commerce in travel for decades, providing virtual real-time connectivity between thousands of suppliers of travel inventory (airlines, hotels, car rental, tour operators, cruise lines, etc.) and hundreds of thousands of retail sellers of travel products.

GDSs progressively consolidated their position to only four major systems, namely Sabre, Amadeus, Galileo and Wordspan (the two latter now both acquired by Travelport, Inc.). This was due to their dominant position as the largest existing repositories of travel inventory information (available airline seats, hotel rooms etc.) with backing from the travel suppliers that had created and funded them (Buhalis \& Licata, 2002). The GDS sector oligopoly was further strengthened by the fact that impressive upfront investment in technology infrastructure was required to run a GDS, effectively raising important entry barriers to new entrants (the Amadeus mainframe centre in Erding, Germany, was said to have the second biggest database after NASA).

GDS platforms evolved from the original airline central reservation systems (CRSs), which were first introduced decades ago. Up to the 1970s, travel agencies had to locate the best routes and fares for their customers in airline manuals and then call the carrier for availability and reservation. The emergence of CRSs not only provided a reservation tool and real-time connectivity to travel agencies but, more importantly, CRSs were effectively transformed into marketing and distribution 
systems which contributed significantly to promoting competition between vendor/host airlines (Boberg \& Collison, 1985; Collier, 1989; Truit, Teye \& Farris, 1991). Each GDS provided airlines with a network of more than fifty thousand selling points worldwide and the ability to customise their offers and prices to meet market conditions. Currently, the three major GDSs combined, handle over 1.4 million travel transactions a year.

After decades of leadership as the carriers' favourite distribution option, GDS firms are now facing a number of changes that threaten their margins and business. These changes (described in section 4 below) are radically transforming the dynamics of airline distribution and the rules of the distribution game.

\section{Latest issues in airline distribution}

\subsection{The shift towards online sales, direct distribution and LCCs}

The emergence of the Internet in the mid-1990s forced airlines to reshape their distribution strategy in order to boost their competitiveness (Buhalis, 2004). At the same time, a number of no-frills airlines emerged in both Europe and the US. Both incumbent and Low Cost Carriers (LCCs) identified the Internet as a major opportunity to tackle distribution costs and to reengineer the structure of the industry (Calder, 2003; Binggeli \& Pompe, 2005).

LCCs were the first to invest heavily in channelling direct sales through their online sales platforms. These airlines developed simple distribution strategies and took full advantage of the Internet bypassing travel agents and GDSs (Oorni \& Klein, 2003). They offered incentives for consumers to book online, in a way forcing their clients online (Chu, 2001). Consumers rapidly identified the Internet and airline Web sites as the platform to benefit from lower prices. In their effort to compete, scheduled carriers, traditionally reliant upon GDS platforms, were forced to follow suit and develop their online presence (Mason, 2001).

Major network airlines are determined to get on a comparable footing with the lowcost carriers (at least for the distribution of their leisure fares) and they are doing so by investing heavily in their direct Web business and reducing their GDS distribution costs. The industry experts consulted by the authors agreed that competition has turned fierce resulting in open price wars. As traditional airlines 
extend their offer of low price tickets, their revenue margins shrink accordingly, and lowering GDS distribution costs becomes an imperative.

The Internet also brought about the appearance of online travel agencies on the marketplace such as Travelocity and Expedia. Online travel agencies, consumer success and high ambitions made airlines react by setting up Orbitz, an online Web site with direct connect technology to airlines, bypassing GDSs and their booking fees. This entity became a powerful competitor to online travel agencies, and it enabled carriers to connect directly via its technology and avoid GDS booking fees. But according to many airline industry analysts, Orbitz also had some unintended consequences: it helped accelerate the commoditisation of online air distribution and put further downward pressure on prices. In short, the airlines successfully addressed one problem (cost of distribution) but fuelled another problem (lower prices), which in turn generated more pressure to lower the cost of distribution.

Most industry experts interviewed by the authors agreed that with these online sales and direct distribution developments, GDSs have found themselves facing the threat of 'disintermediation' and 'commoditisation'. As airlines go direct, GDSs seem no longer necessary or at the very least, with the appearance of online alternatives to GDSs, their product seems to become a commodity that does not justify a high booking fee. Our review of air distribution industry literature showed that the GDSs have reacted against the threats posed by the shift to online direct bookings in three ways: first they developed internet based technology, providing the transactional infrastructure for Internet travel portals. Secondly, they reinvented themselves as main technology suppliers for airlines, extending their technology offer to a wider range of ICTs and technology consultancy services. Finally, GDSs have tried to pre-empt the airlines' Web sites by establishing their own online travel agency Web sites, such as Travelocity (owned by Sabre) or Opodo (owned by Amadeus).

Despite GDS and travel agency efforts to protect an intermediary based distribution model, carriers' direct share of online air ticket sales in the US reached $61 \%$ of the online market versus 39\% for Online Travel Agencies (OTAs) (PhoCusWright, 2008). According to the same source this balance is projected to hold steady through 2010, although intense competition and tumultuous dynamics underlie this equilibrium. The airlines corporate web sites have been enjoying considerable growth year over year, and their marketing initiatives are driving customer loyalty 
and a powerful shift in consumer behaviour. The experts asked by the authors agreed that this level of activity on the part of airlines will continue in an effort to shift more and more share from the online agencies to their corporate web sites.

These developments mean that the traditional GDS model, based purely on travel agency distribution, has been eroded by the shift to airline direct online sales. The increase in airlines' negotiating power became apparent in the latest rounds of GDS-airline contracting that essentially focused on the cost of distribution for discounted leisure fares where it is said that airlines have achieved discounts of up to $40 \%$ in their booking fees (Quinby, 2006). The leisure travel segment is the one where airlines have the most leverage, yet these are the products which have the highest relative cost of distribution.

Most experts consulted agreed that those suffering the most from the shift to online direct sales are traditional travel agencies and that they do not expect all travel agencies to survive this era. The new airlines-endorsed GDS programmes for agencies impose steep cuts in incentive payments and allow for charges to be paid to the airline in case of selling low-value tickets (see Figure 2 below for the new paradigm in the airline-GDS-travel agency relationship).

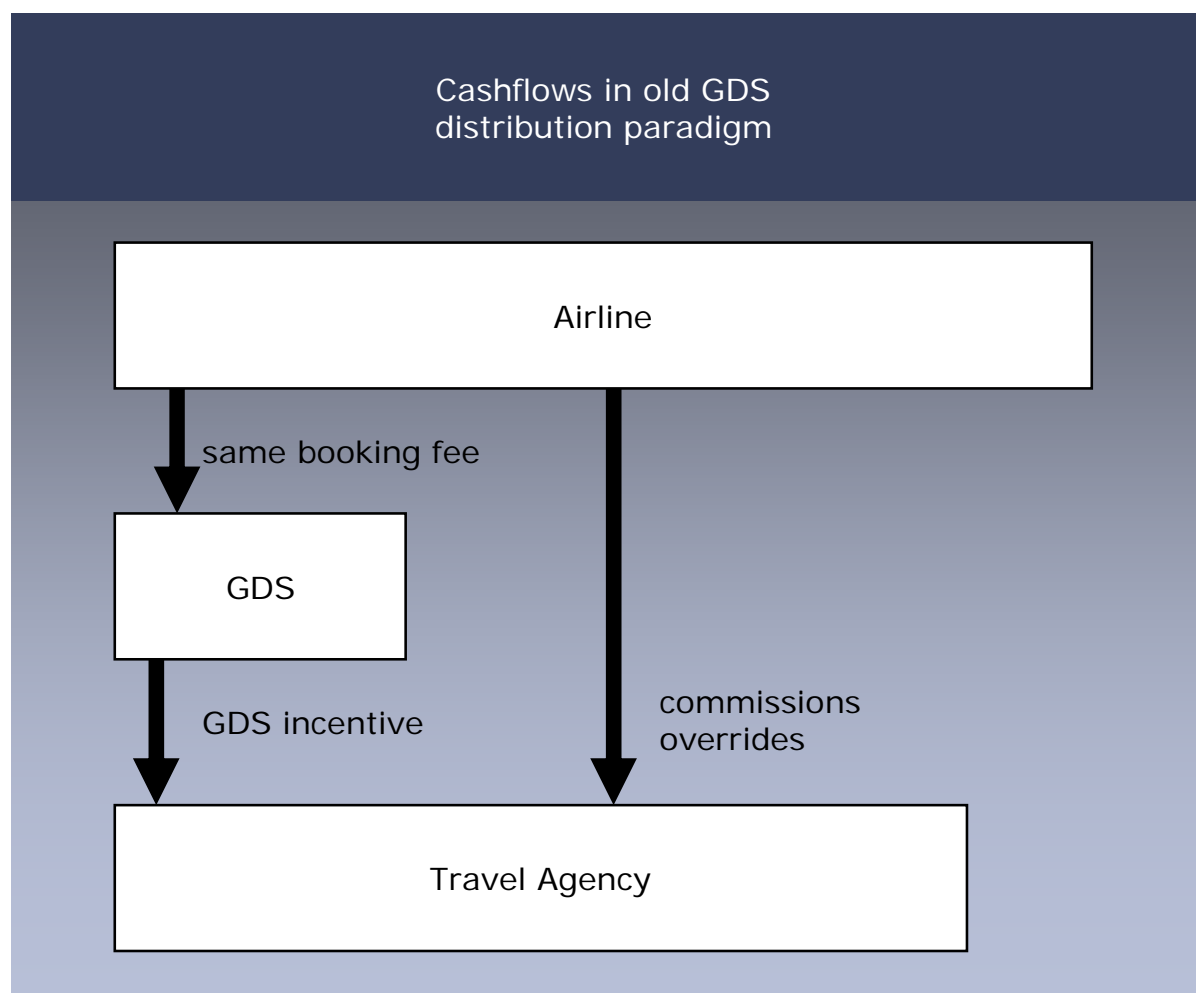




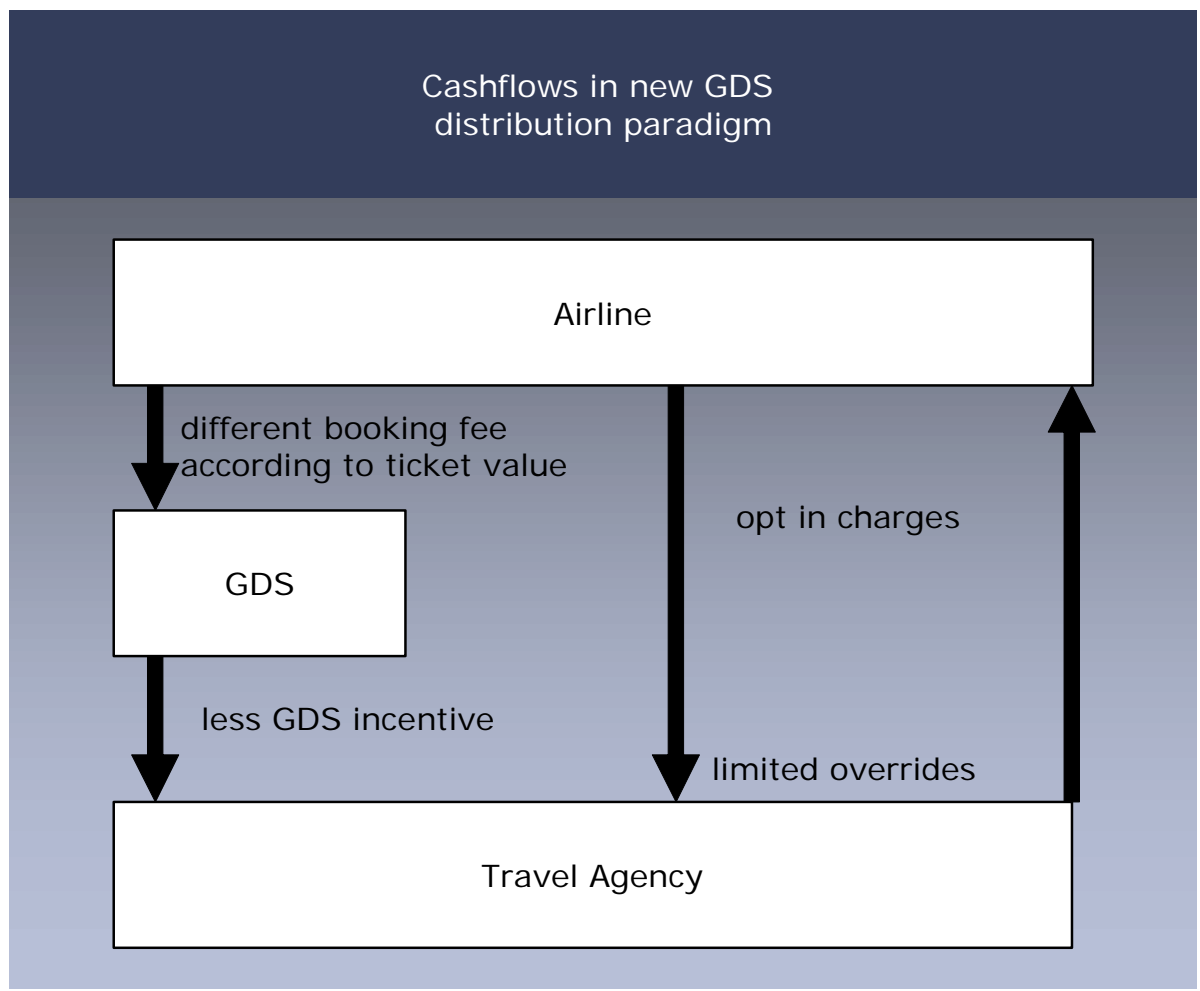

Figure 2. "Changing GDS model". Source: authors

The shift is more obvious in the US (facilitated by GDS deregulation in 2004) but is also the trend in Europe. Lufthansa and its Swiss subsidiary initiated in 2008 in Germany, Austria and Switzerland a $€ 4.90$ per-way surcharge plus value-added tax on fares booked through the Amadeus GDS. As a result Amadeus is losing significant market share in Germany ( $10 \%$ loss in two months, Air and Business Travel News, 2009).

\subsection{Growth and risks in air travel demand}

At the level of air travel, demand is growing worldwide as a result of economic development, globalisation, international trade, cheaper passenger fares and improved airline services. World airlines have experienced average traffic growth of around 5\% per year in the last 10 years and industry analysts (Boeing Current Market Outlook, 2008) project that world air traffic demand will grow in the next 20 years at an annual rate of $5 \%$.

Despite such phenomenal growth projections, industry analysts maintain that air travel demand is subject to a series risks such as economic downturns, unpredictable geopolitical events, rising fuel costs and environmental concerns. 
Uncertainty in all these areas makes airlines vulnerable to the future and presses them to streamline costs (including distribution) as much as possible in order to shield themselves against potential falls in demand and/or revenue margins.

\subsection{GDS deregulation}

The US and Europe regulated the GDS sector in the 1980s. These regulations were introduced at a time when GDSs were owned by airlines and there was a visible threat that GDSs would give preferential treatment to their owners (for example a biased display of the airline's flights on the travel agent's screen) and jeopardise fair competition.

As airlines divested their stakes in their GDSs and the Internet widened up the distribution and buying choices for airlines and end consumers respectively, regulators felt that it was no longer necessary to protect the market. In 2004, GDSs were deregulated in the US and the European Commission is currently examining whether to partially revise or fully abolish its Code of Conduct for CRSs (in Europe, Amadeus is still partly owned by Iberia, Air France and Lufthansa and hence the discussion on a partial instead of full deregulation).

Deregulation led to a new state of affairs where airlines are no longer obliged to participate equally in all GDSs and can steer business to selected GDSs. Biased seat availability displays are no longer prohibited and airlines can freely negotiate booking fees and level of participation in each GDS.

As a result of GDS deregulation in the US and the prospect of an amended deregulation in Europe, GDSs are changing their business model, allowing for more flexibility in their pricing (Alamdari \& Mason, 2006). But, according to the same authors, what deregulation effectively means is additional pressure on GDS margins with $60 \%$ of airlines seeing deregulation as an opportunity to gain greater control over their distribution channels and to establish their relationship with GDS companies on a "value for money" basis.

\subsection{Technological advances}

As mentioned earlier in section 3, an important entry barrier to the GDS business has been the GDS model's reliance on a formidable technological platform. GDSs based their system architectures on mainframe computing platforms running TPF, 
IBM's durable Transaction Processing Facility OSS. These platforms served GDSs and airlines well for decades because of their ability to handle huge transaction volumes (up to ten thousands per second) with superb reliability and response times. They deliver secure systems with a 99.9\% assurance of connectivity, response times of a fraction of a second and allow them to offer highly accurate and comprehensive fares and pricing systems worldwide and process billions of travel transactions monthly.

With the Internet explosion, GDSs with their legacy mainframes were described as dinosaurs. The GDS applications designed decades ago have been repeatedly amended to accommodate new functionality, each time adding complexity and cost. But since the emergence of more flexible Internet-based technologies in the 1990s, flexibility and open architecture have become key requirements in the market (Quinby, 2005). New technology not only makes it easier to write applications in modern programming languages with an emphasis on adaptability and ease of integration with other systems, it also allows such applications to be run on PC-class servers running Linux OS, offering a major up-front cost advantage over IBM mainframes in terms of hardware and software licenses.

Based on our primary and secondary research, we can conclude that such technological breakthroughs have had a dual impact on GDSs. On the one hand they have lowered the entry barriers and opened a window of opportunity for new entrants in the sector and on the other hand they constitute a big expense item to GDSs who, in order not to become obsolete, are obliged to migrate their legacy systems to open system architecture. All GDSs are currently engaged in costly exercises of moving towards an open system architecture (our industry sources suggested that Amadeus have invested more than one billion euros in the migration project).

\section{GDS New Entrants (GNEs)}

This changing environment with its hassles for the GDS industry gave rise in 2005 to a number of companies - including Triton Distribution Systems, ITA Software, G2 Switchworks and Farelogix- which all claimed that they were developing GDS alternatives. In an environment where airlines were complaining about the cost of distribution and calling for an end to the oligopoly of GDSs, the new entrants 
promised to offer big discounts in supplier segment fees and more flexible and functional distribution technology.

One of these GNEs, G2 SwitchWorks, is a Chicago based company founded by a team of former Orbitz executives. Another, Cambridge, Massachusetts-based company, ITA Software, played a key role in the Orbitz technology platform and is today a leader in airfare shopping and pricing technology. Farelogix is Miami-based and offers an application layer (the FLX Platform) that enables distributors to aggregate and manage content from multiple sources, including GDSs, the Internet and direct connects to suppliers' reservation systems. Its CEO does not see it as an alternative GDS but rather as a bridging solution to enable agencies to better manage inventory sourcing from multiple channels. Having said this, the firm is offering direct connectivity to some airlines, effectively making it an alternative channel for suppliers to distribute to agencies (Quinby, 2006).

Our research indicates that GNEs received considerable attention in 2005 when they announced an estimated pricing for suppliers at a considerable discount from the existing GDS fee levels of USD 2.00-2.50 per booking. Triton and G2 SwitchWorks promised savings upwards of $75 \%$ of GDS costs, while ITA suggested pricing could start around 40 cents per segment for its alternative GDS offering. Furthermore, GNEs promised improved product and service, emphasising that building their systems from scratch allowed them to design flexible systems with a focus on customer-centric functionality. Amongst others, GNEs offered unlimited capacity for new products and services, new products for airlines such as private fares and preferred display of inventory to authorized agencies, interoperability with any back-end system eliminating the integration burden, scalability through Service Oriented Architecture and secure direct connections to air carriers.

However, three years ahead it is still very uncommon for a travel agency to operate without the use of at least one of the big four GDS systems. Despite the announcement of several major agencies in beta testing and important supplier deals from G2 Switchworks and Farelogix, GNEs accounted for well under $1 \%$ of the US domestic market for segments in 2006 (Quinby, 2006). According to the interviews held with GDS experts, GNEs never managed to increase their market share and have been obliged to reposition themselves as providers of airline related software technology rather than GDSs. 


\section{The reasons behind GNEs' initial failure to provide an alternative to GDSs}

GNEs have yet to live up to their expectations, as their market penetration has been minimal. Our research suggests that instead of migrating to the new GDS promising environment the airlines have used the GNE offer as a negotiation tool in their expiring contract negotiations with the GDSs. Major carriers have apparently won substantial concessions (30-40\% discounts) and achieved many of their goals in these negotiations. Why have GNEs (when they seemed to address the two most crucial airline concerns, superior technology and cost of distribution) failed up to now to win market share from GDSs? Our research revealed that there are three main reasons for this:

\subsection{Overestimation of technology offer}

GNEs' direct connect promise has remained unfulfilled. To date only the major online agency, Orbitz, has implemented airline direct connects that bypass GDSs, and only with a limited number of major U.S. carriers. Our research suggests that one big barrier to direct connect implementation are the technical challenges, especially in the corporate marketplace, related to meeting the rigorous and complex requirements for fulfilment, exception handling and back-office integration set by travel management companies (TMCS). Capability to meet these requirements, which GDSs have already invested in heavily to support, add to the cost and complexity of interfaces. Another big barrier identified in our research is meeting the equally complex requirements set by airline alliances and airlines' interlining needs. GNEs' technology is of course open source and flexible but it has not yet been developed to cover the full functionality currently provided by GDSs.

\subsection{GDSs retaliated with updated technology and offering concessions}

Our study of the industry press revealed that GDSs did not remain impervious to the GNE threat. All major GDSs introduced to a greater or lesser extent important changes to their pricing models substituting their originally "same price for all segments fees" with channel based pricing schemes, distinguishing for example between direct and travel agency sales, domestic and international flights or between leisure and corporate segments. This way they managed to offer concessions to airlines in the most price sensitive low cost segments whilst maintaining higher fees for the higher value tickets. 
As the experts interviewed pointed out, GDSs also introduced innovations at the technology level. First, as seen in section 4, they have all started migration programs to open architectures and secondly they are developing new products and functionality to adapt to the ever changing needs of the sector. For example, for smaller airlines and low cost carriers they developed the ability to connect to a GDS network using XML Application Programming Interfaces (APIs), which allows airlines to connect to the GDS with a simpler protocol, and even opt for alternative arrangements where an airline prices the itinerary instead of relying on third party fare filing requirements and the GDS' pricing engine.

\subsection{They overlooked the travel agency side of the equation}

While GNEs generated vast interest from airlines because of their proposition to reduce the cost of distribution, GNE penetration into the agency side of the equation remained scarce (see section 5 ). On the other hand, GDSs offer suppliers worldwide distribution to thousands of travel agencies, both traditional and online. We can thus conclude (and our experts agree) that without guaranteed booking volume, lower distribution fees have no meaning to airlines.

GDSs accounted for $59 \%$ of all flights segments booked in 2006 (PhoCusWright Market Research, 2007), and while this share is declining gradually, it still represents a substantial portion of the total marketplace. According to the same source, remove low-cost carriers such as Southwest, JetBlue and AirTran (all of which generate a far greater portion of their sales through their Web sites) from the segment share assessment, and the GDS segment share gets much closer to $70 \%$. In other words, network carriers remain dependent upon GDSs (and their network of travel agencies) for a substantial majority of their sales.

One of the reasons why travel agencies did not buy into the GNE model was that the level of content and functionality offered to them was inferior from the one supplied by GDSs (Quinby, 2006). GDSs have, over many decades and after serious investments, managed to develop an almost one-stop-shop content and sales platform for travel agencies. GDSs offer aggregated content (all major airlines, hotels, car rental companies and many cruise lines and tour operators), global offering, proven, $99.9 \%$ reliable networks, interline capabilities, guaranteed airline pricing, established customer service support, ancillary vendors, highest security for personal data, innovative products to help agencies such as group 
capabilities and all kinds of front, mid and back-office solutions for travel agencies to handle the full reservation process. GNEs came onto the market with a far more limited product for the agencies.

Most importantly, GDSs offer agency incentives for reaching goals. To cut down the cost to the airline, GNEs abolished the incentives paid to the travel agency and claim to replace it with better fares content from the airlines. But agencies and travel management companies are not encouraged if there are no attractive incentive schemes.

\subsection{GDSs lead to higher value customers}

Not only do GDSs give access to a wide travel agency network but, most importantly, GDSs seem to steer to "higher yield" customers. Indeed, JetBlue VP Revenue Management R. Zeni has said that tickets sold through GDSs have a USD30 average fare premium over those sold via its own Web site, JetBlue.com. This is so because a significant majority of corporate travel is booked through travel agencies and GDSs, including bookings generated from online corporate booking tools. Currently, nearly $81 \%$ of online corporate bookings and $75 \%$ of offline transactions go through intermediaries, traditional and Internet travel management companies (PhocusWhright, 2008) who use GDSs for almost all transactions and who, as seen in section 6.3 above, are reluctant to migrate to a GNE platform. Furthermore, many large corporations are using automated tools that sit on top of GDS technology, to manage their employee travel needs, which makes the switch to a GNE even more challenging.

Another important aspect for business travellers is the possibility to reserve complex itineraries on both a national and international basis. Such itineraries are only possible when the reservation system allows 'interlining' that is the ability to see (and reserve) in a single availability display which flights can be combined to reach a specific destination. GNEs still lack this capability.

Because of the higher margins it provides, the corporate travel segment not only attracts traditional carriers. Recently, more and more LCCs are making efforts to get business from this segment.

In order to make their product accessible to large corporations, Low cost carriers (LCCS) need to have their offer fully integrated into corporate travel tools, which is 
now only possible if they participate in the main GDSs. Full integration would for example allow corporate travellers to compare the LCC offer with traditional carriers on a single availability search (on the contrary, the lack of real-time comparison makes the travel purchase process more complex and cumbersome).

LCCs want to enter the higher-yield segment available via GDSs without losing their customers to online agencies. A good example of how LCCs take advantage of the GDS model is JetBlue, which negotiated to provide the full range of its discounted fares to traditional travel agencies but only through the designed corporate bookings tools. This gave JetBlue a way to win new business travellers without eroding bookings on its website.

\section{Conclusions, limitations and future research}

In this paper we have examined the latest developments and transformations in airline distribution, triggered mainly by the emergence and growth of the Internet and open architecture technologies. We have presented the key changes affecting the GDS industry as identified and described by airline distribution research analysts. In this context, a key focus and contribution point of our study has been the detection and description of the reasons behind GNEs' failure to provide an alternative distribution channel in the marketplace.

As seen, despite the predictions that the GDS business would disappear, GDSs still account for nearly $60 \%$ of all air segments booked in the US market and all major GDSs continue to enjoy healthy growth and margins. Industry experts agree that the prospect of major carriers withdrawing from GDSs in the short term is becoming increasingly unlikely as GDSs cut prices and shift to a more diversified range of airline technology solutions, embracing a role of integrated technology partners.

Our analysis suggests that the GDS success stems from a set of asset pre-emption mechanisms. These assets included the creation of network externalities and an established reputation with suppliers and distributors that allowed GDSs to raise significant entry barriers for new entrants who had to recreate from scratch the commercial network developed by the GDSs. The advantages enjoyed by GNEs such as access to cheaper and more efficient technology, better adaptability to the 
new dynamic needs of the Internet era and organisational flexibility did not suffice to overcome their main disadvantage, that is lack of marketing capabilities.

Lieberman and Montgomery (1988) suggest that if one firm has unique $R \& D$ capabilities while the other has strong marketing skills it is in the interest of the first firm to pioneer and the second firm to enter at a later date. Both may earn significant profits entering in this sequence, but neither would gain if the order to entry were reversed. Applying this logic to airline reservation systems, it seems reasonable to suggest that new players challenging the leadership of traditional GDSs should as a minimum to be able to demonstrate superior marketing capabilities than incumbent players, at least in a niche market.

Nevertheless, the distribution power game is by no means over yet, as market conditions are still very dynamic (Buhalis, 2008). First of all, GDS deregulation has still not shown its full impact; deregulation is still not the case in Europe and the rapidly growing Asian markets, and airlines still make their content available to all GDSs and travel agencies. But this could change and in the future airlines might not commit themselves to providing all of their content to GDSs. According to the experts asked, this would put additional downward pressure on GDS fees and GDSs would need to seek out alternative sources of value to their service to justify their prices. Secondly, airlines remain focused on driving business through their own corporate Web sites, taking an increasingly higher number of booking transactions away from both online travel agencies and GDSs (PhoCusWright, 2008). Finally, as Henderson and Clark (1990) assert, if the shift to the new generation is radical enough, incumbents will be hampered by their existing capabilities. i.e. they will be unable to adapt. GDS new entrants could become relevant players in the travel distribution scene if they shifted their focus to building capabilities (technical and marketing) in new areas where traditional GDSs are weak: i.e. internet technology for direct airline channels or platforms with access to many GDSs simultaneously. This window of opportunity makes the experts asked believe that despite their initial failure, GNEs could be here to stay.

Similar to most studies, this paper is subject to limitations. The authors have based their analysis on the available literature on airline distribution (both academic and industry studies), on interviews held with a small number of airline and airline distribution industry experts and on the authors' knowledge from their professional experience in the GDS industry. Whilst a wide variety of comments, 
articles and reports have been published in industry publications, academic studies on airline distribution are relatively scarce. Without wanting to undermine the quality and depth of analysis of industry sources, academic studies might be regarded by the readers of our paper as more relevant research material. Thus, we advocate the importance of further academic research on airline distribution systems. Another limitation to our study has been that the number of experts consulted was relatively small (six) to permit us to accompany many of the opinions presented using a more scientific approach, such as for example a structured Delphi study.

With regards to future directions, the authors feel that the analysis of future trends in the airline-GDS-Travel agency equation could be the subject of a broader and more systematic experts opinion study that could predict with more precision the shift in distribution power and investigate trends such as the impact of Open Source technologies, web social networks and mobile travel applications on the airlines' distribution strategies.

\section{References}

Airbus. (2007). Global Market Forecast 2007-2026. Retrieved October 19 ${ }^{\text {th }}, 2008$ from http://www. airbus.com/en/corporate/gmf/

Air and Business Travel News (2009). Amadeus faces massive loss over fares scheme. Retrieved on April $4^{\text {th }}, 2009$ from http://www.abtn.co.uk/news/amadeusfaces-massive-loss-over-fares-scheme.

Alamdari, F., \& Mason, K. (2006). The future of airline distribution. Journal of Air Transport Management, 12(3), 122-134.

Association of European Airlines. (2007). Yearbook 2006. Brussels.

Binggeli, U., \& Pompeo, L. (2005). The battle for Europe's low-fare flyers. McKinsey Quarterly, August. Retrieved on April $1^{\text {st }}, 2009$ from http://www.mckinseyquarterly.com/Transportation/The_battle_for_Europes_lowfare_flyers 1656

Boeing Current Market Outlook. (2008). Retrieved October $19^{\text {th }}, 2008$ from http://www.boeing.com/commercial/cmo/index.html 
Boberg, K., \&.Collison, F. (1985). Computer Reservation Systems and airline competition. Tourism Management, 6(3), 174-183.

Buhalis, D., \& Law, R. (2008). Progress in tourism management: Twenty years on and 10 years after the Internet: The state of eTourism research. Tourism Management, 29(4), 609-623.

Buhalis, D. (2004). eAirlines: strategic and tactical use of ICTs in the airline industry. Information \& Management, 41, 805-825.

Buhalis, D. (1998). Strategic use of information technologies in the tourism industry. Tourism Management, 19(3), 409-423.

Buhalis, D., \& Licata, M.C. (2002). The future eTourism intermediaries. Tourism Management, 23(3), 207-220.

Calder, S. (2003). No Frills. The Truth Behind The Low Cost Revolution In The Skies. London. Virgin Books.

Chu, R. (2001). What online Hong Kong travelers look for on airline/travel websites? International J ournal of Hospitality Management, 20(1), 95-100.

Collier, D. (1989). Expansion and development of CRS. Tourism Management, 10(2), 86-88.

Copeland, D. (1991). So you want to build the next SABRE System. Business Quarterly, 55(33), 56-60.

Copeland, D., \& McKenney, J. (1988). Airline reservation systems: Lessons from history. MIS Quarterly, 12, 535-570.

Dennis, N. (2007). End of the free lunch? The responses of traditional European airlines to the low-cost carrier threat. Journal of Air Transport Management, 5, 311-321.

Dobruszkes, F. (2006). An analysis of European low-cost airlines and their networks. J ournal of Transport Geography, 14, 249-264.

Eurocontrol, (2007). Low Cost Carrier Market Update. Retrieved on April 20 ${ }^{\text {th }}, 2009$ from 
http://www. eurocontrol.int/statfor/gallery/content/public/analysis/LowCostMarket UpdateDec06_V01.pdf

European Commission (2006). ICT and eBusiness in the Tourism Industry. ICT adoption and eBusiness activity in 2006. Retrieved on April $20^{\text {th }}, 2009$ from http://www. ebusiness-watch.org/studies/sectors/tourism/tourism.htm

Franke, M. (2004). Competition between network carriers and low-cost carriersretreat battle or breakthrough to a new level of efficiency? Journal of Air Transport Management, 10, 15-21.

Gholami, R., Emrouznejad, A., \& Schmidt, H. (2008). The Impact of ICT on Productivity of Airline Industry. RP0809. Operations and Information Management. Aston Business School.

Henderson, R.M., \& Clark, K.B. (1990). Architectural Innovation: The Reconfiguration Of Existing Product Technologies and the Failure of Established Firms. Administrative Science Quarterly, 35(1), 9-30.

Inkpen, G. (1994). Information Technology for Travel and Tourism. Pitman.

Jacobsen, M., Batarow, D., \& Bode, M. (2008). IT Innovation in Tourism: IT Innovation as Driver of Tourism. Retrieved on April $1^{\text {st }}, 2009$ from http://www. wi.uni-muenster. de/WI/studieren/io/ws0809/essay $\% 5 \mathrm{ClE08}$ essay IT_innovation_in_tourism.pdf

Laudon, K.C., \& Laudon, J.P. (2007). Management Information Systems. New Jersey. Prentice-Hall.

Lee, S. (2001). Modeling the business value of information technology. Information \& Management, 39(3), 191-210.

Lieberman, M.B.; \& Montgomery, D.B. (1988). First-Mover Advantages. Strategic Management J ournal, 9, 41-58.

Mooney, M. (2003). The issues and challenges of a pricing system implementation. Journal of Revenue and Pricing Management, 2(2), 116-119. 
OAG Travel Information. (2006). European Low Cost Carriers White Paper.

Retrieved on April 20 $0^{\text {th }}, 2009$ from

http://www. oag.com/graphics/lowcostcarriers.pdf

O'Conner, P. (1999). Electronic Information Distribution in Tourism and Hospitality. CABI Publishing.

PhoCusWright Market Research. (2007). European Online Travel Overview. Third Edition. PhoCusWright Market Research.

PhoCusWright Market Research. (2008). PhoCusWright's U.S. Online travel overview. Eighth Edition. PhoCusWright Market Research.

Poon, A. (1993). Tourism, technology and competitive strategies. Oxford: CAB Internetional.

Porter, M. (2001). Strategy and the Internet. Harvard Business Review, 103D, 6378.

Porter, M. (1985, Winter). Technology and Competitive Advantage. The Journal of Business Strategy, 60-70.

Quinby, D. (2005). GeNiEs: Marketing or Magic?. The PhoCusWright Snapshot. PhoCusWright Market Research.

Quinby, D. (2006). Un Uneasy Peace: Airlines, GDSs, GNEs and the Outlook for Air Travel Distribution in the North American Marketplace. The PhoCusWright Snapshot. PhoCusWright Market Research.

Truitt, L.J., Teye, V. B., \& Farris, M.T. (1991). The role of computer reservations systems: International implications for the travel industry. Tourism Management, 12(1), 21-36.

Verville, J. (2003). A Process Approach for Selecting ERP Software: The Case of Omega Airlines. Annals of Cases on Information Technology, 5, 26-34

Werthner, H., \&; Klein, S. (2005). ICT-enabled Innovation in Travel and Tourism. Innovation and Product Development in Tourism, 7184. 
Werthner, H., \& Klein, S. (1999). ICT and the Changing Landscape of Global Tourism Distribution. Electronic Markets, 9(4), 256262.

Article's contents are provided on a Attribution-Non Commercial 3.0 Creative commons license. Readers are allowed to copy, distribute and communicate article's contents, provided the author's and Journal of Industrial Engineering and Management's names are included. It must not be used for commercial purposes. To see the complete license contents, please visit http://creativecommons.org/licenses/by-nc/3.0/. 